\title{
ANGEL RAMA O LA CRITICA COMO GOZO
}

\author{
POR \\ TOMAS ELOY MARTINEZ \\ University of Maryland
}

A fines de los años cincuenta, las páginas culturales de la revista Marcha y de los diarios El País y El Día, que se publicaban en Montevideo, se convirtieron en la única brújula de referencia crítica para los jóvenes creadores de la Argentina. Eran, en Buenos Aires, tiempos de confusión y desconcierto.

Desde los años de apogeo del modernismo, cuando un artículo elogioso de Leopoldo Lugones sembraba para siempre la gloria de un autor (así había sucedido con la canonización de Martín Fierro en 1916 y con la de Don Segundo Sombra una década después), las tablas del gusto literario eran dictámenes de autoridad que se propalaban desde la revista Sur y el suplemento dominical del diario La Nación. Quien no publicase o fuese alabado allí estaba condenado a la marginalidad y al desdén. En los salones de la alta burguesía se exhalaban promiscuamente frases de Lin Yutang, de Aldous Huxley y George Santayana, éxitos editoriales del momento.

Pero hacia adentro, en el feudo propio, el prestigio solía guardar relación inversa con la popularidad. Vender mucho no era de buen tono. Aquel Parnaso contaba con dos dioses seguros, que se repartían las bienaventuranzas del poder: Eduardo Mallea y Victoria Ocampo. Detrás, en tropel, asomaban Manuel Mujica Láinez, Adolfo Bioy Casares, Eduardo González Lanuza y el consejo de redacción en pleno de la revista Sur. Arriba y al costado brillaba, incontestable, Borges. No faltaban los ángeles caídos, como Leopoldo Marechal, que se había pasado al peronismo y a quien estaba prohibido nombrar - como sucedió con el propio Perón luego de su derrocamiento en 1955—, ni los exiliados apocalípticos, como Ezequiel Martínez Estrada; tampoco los geniecillos iconoclastas, a quienes se toleraba cualquier impertinencia porque habían sido elegidos, desde su 
misma irrupción en el Parnaso, para heredar todo el poder y las promesas de los dioses: tal era el caso de H. A. Murena.

En la vereda de enfrente, una facción de jóvenes recién egresados de la Facultad de Filosofía y Letras - cuyos claustros y cafés de combate eran, por lo demás, contiguos al edificio de Sur-, emprendían desde revistas como Verbum, Centro y, en especial, la legendaria Contorno la demolición sistemática de todo ese pasado. Concentrada en el análisis de la novela argentina y de la lengua como objeto social, armada con flamantes instrumentos críticos que derivaban de la lectura de Sartre y de Les Temps Modernes, Contorno erigió lo que se ha llamado «una poética anti-Sur», que culminó con el rechazo furibundo a la obra de Mallea, el ajuste de cuentas con Borges y Martínez Estrada y la exaltación de Roberto Arlt, a quien Sur, inversamente, había ignorado por completo ${ }^{1}$.

La casa estaba en desorden y las pasiones, inconciliables, impedían ver slaro. Fue entonces cuando, desde Uruguay, la que Angel Rama designaría como "generación crítica», enseñó a ver el mundo (y sobre todo el continente propio) de una manera inédita. En vez del mero análisis del discurso literario, empezó a examinarse la ideología de la cual brotaba ese discurso, las estructuras políticas y sociales del país que lo generaba, los corsi e ricorsi de los prejuicios, de los medios de comunicación y de los receptores del texto. La literatura no fue considerada como un fenómeno aislado dentro de la panoplia de las artes: Rama, que se había ejercitado en el teatro como autor y - de modo incipiente- como actor, y para quien el cine, la ópera y la plástica eran panes de conocimiento cotidiano, fue de los primeros en advertir que, concertando todos esos afluentes, se abrían para cualquier texto nuevos caminos de iluminación.

El método (más que el recurso) de la generación crítica consistió, pues, en abarcarlo todo: en comprender que la palabra sólo manifiesta la plenitud de su riqueza cuando es leída en el contexto de su entera realidad. Rama se internó más que nadie en ese camino que había empezado a desbrozar él mismo. Adiestrado en la gimnasia de los liceos y de los periódicos, aprendió sobre la marcha a esquivar la sofocación de las elucubraciones teóricas puras. A la inversa de los imitadores de Barthes y de Foucault, que tanto proliferarían después en las academias de América Latina, Rama jamás escribió artículos meramente teóricos, sino que insertó la teoría en el análisis de textos particulares. Y si a partir de tal análisis se le hacía necesario reformular la teoría, no se amedrentaba. Un ejemplo

' Carlos Mangone y Jorge Warley, Prólogo a Contorno, selección de artículos de David Viñas, Ismael Viñas, Juan José Sebreli, Noé Jitrik, León Rozitchner, Oscar Masotta y otros (Buenos Aires: Centro Editor de América Latina, 1981). 
memorable son las lentas y sutiles vueltas de tuerca con que, al analizar las últimas novelas sobre dictadores latinoamericanos, fue refutando la noción de «individuo histórico» que Lukács creía consustancial al género biografía novelada, y la sustituyó por un concepto más complejo: el de la instalación del narrador en «la conciencia misma del personaje», para poder interrogar así «directamente al poder omnímodo» y observar «su pleno funcionamiento» ${ }^{2}$.

Si Rama y sus congéneres desempeñaron un papel primordial en la mitología literaria de los años cincuenta fue porque supieron captar más rápido y mejor que nadie las transformaciones culturales de la época ${ }^{3}$. Fueron los primeros en descubrir a Ingmar Bergman y en prodigar extensos análisis sobre su opera omnia, que sólo ellos lograban ver en las salas de arte de Montevideo. Libres de pasiones parroquiales, abrieron las puertas de sus revistas tanto a Borges como a su detractor David Viñas, y sus editoriales a Juan Carlos Onetti y a Felisberto Hernández; se adelantaron a narrar las aventuras de un puñado de ignotos guerrilleros en Sierra Maestra, a desenmarañar los duelos entre el yo y la realidad que se libraban en las novelas de Samuel Beckett - aún no traducidas- y a percibir en las improvisaciones de John Coltrane y de Miles Davis los ecos del difunto Charlie Parker. Nadie sabía de dónde sacaban tiempo para explorar tanta información y para procesarla con inteligencia. Todos ellos publicaban un par de largos artículos por semana, un libro al año, dictaban cursos y conferencias, eran editores y viajeros.

Hasta Buenos Aires solían 1legar, mitigados, los ecos de las batallas de inteligencia que oponían entonces a Emir Rodríguez Monegal -crítico de El País, célebre ya por sus sarcasmos contra los admiradores de Sartre y:

${ }^{2}$ A. R., Los dictadores latinoamericanos (México, D. F.: Fondo de Cultura Económica, 1976); las citas corresponden a las páginas 24-26 y 16. Variantes de esos textos fueron publicadas en el "Papel Literario» del diario El Nacional, Caracas, 1 de junio de 1975 , p. 1 («Una remozada galería de dictadores»), y 15 de enero de 1975, p. 1 («La novela como poema cíclico»); en Revista de Literatura Hispanoamericana, Universidad del Zulia, Maracaibo, enero-junio de 1975, pp. 9-47; y en $E c o$, Bogotá, agosto de 1975, pp. 408-442. Una versión final fue publicada por Colcultura en Bogotá, 1982, junto a otros artículos dispersos, en el volumen La novela latinoamericana. Panoramas 1920-1980.

${ }^{3}$ Rama concedía notable importancia al juicio que un crítico era capaz de aventurar sobre sus contemporáneos y a la pertinencia con que advertía los fenómenos centrales de su propia época. Así, en «El manifiesto fundacional» encomia la exactitud con que Alberto Zum Felde en 1954 y José Martí hacia fines del siglo XIX subrayan el condicionamiento que impone a un producto cultural su dependencia: de los factores comarcales; del mismo modo, en «La novela-ópera de los pobres». pondera la temprana valoración que Mario Vargas Llosa hizo del manejo de la lengua de los personajes indios en Los ríos profundos de José María Arguedas. 
Lukács, que proliferaban en ambas márgenes del Plata - con Angel Rama, quien desde Marcha imponía una visión sociológica, comprometida, de los fenómenos culturales. Fue un tenaz combate que siguió librándose en otras ciudades durante más de un cuarto de siglo, sin que jamás «hubiese un

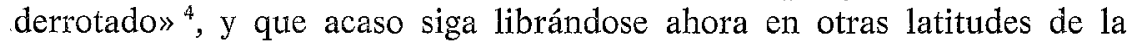
eternidad, como en un cuento de Borges.

Pido en este punto que se me consienta una digresión personal. No encuentro medio mejor que la íntima memoria para transmitir el contagio de vida que se desataba en la relación intelectual con Rama.

En el invierno austral de 1958 yo era un joven crítico cinematográfico de Buenos Aires que se drogaba cada semana con los ejemplares canónicos de Marcha y El País. No es difícil imaginar, entonces, la profunda 'sensación de buena suerte que me sobrecogió cierta mañana, cuando recibí un convite para dictar dos conferencias en el Cine Club de Montevideo. Si acepté fue sólo porque confiaba en encontrarme al fin con los maestros.

En el puerto de la Ciudad Vieja me recibió el propio Rama. Todavía

${ }^{4}$ Prólogo de Mario Vargas Llosa a La ciudad letrada (Hanover, New Hampshire: Ediciones del Norte, 1984), pp. III-VIII. Vale la pena citar in extenso el párrafo inicial del trabajo de Vargas Llosa:

«Los Congresos de Literatura serán más aburridos ahora que Angel Rama no puede asistir a ellos. Verlo polemizar era un espectáculo de alto nivel, el despliegue de una inteligencia que, enfrentándose a otras, alcanzaba su máximo lucimiento y placer. Me tocó discutir con él algunas veces, y, cada vez, aun en lo más enérgico de los intercambios, aun mientras nos dábamos golpes bajos y poníamos zancadillas, admiré su brillantez y su elocuencia, esa fragua de ideas en que se convertía en los debates, su pasión por los libros, y siempre que leí sus artículos sentí un respeto intelectual que prevalecía sobre cualquier discrepancia. Tal vez por eso, ni en los momentos en que nuestras convicciones se alejaron más, dejamos de ser amigos. Me alegro haberle dicho, la última vez que le escribí, que su ensayo sobre La guerra del fin del mundo era la que más me había impresionado entre todas las críticas a mi obra. Desde que supe su muerte, no he podido dejar de recordarlo asociado con su compatriota, colega y contrincante de toda la vida: Emir Rodríguez Monegal. Todo organizador de simposios, mesas redondas, congresos, conferencias y conspiraciones literarias, del Río Grande a Magallanes, sabía que con- seguir la asistencia de Angel y Emir era asegurar el éxito de la reunión: con ellos presentes, habría calidad intelectual y pugilismo vistoso. Angel, más sociológico y político; Emir, más literario y académico; aquél más a la izquierda, éste más a la derecha, las diferencias entre ambos uruguayos fueron providenciales, el origen de los más estimulantes torneos intelectuales a los que me ha tocado asistir, una confrontación en que, gracias a la destreza dialéctica, la elegancia y la cultura de los adversarios, no había nunca un derrotado y resultaban ganando, siempre, el público y la literatura.» 
recuerdo el esplendor de su carcajada, el extremo interés con que atendía mis comentarios triviales, el abanico de erudición que desplegó invocando nombres que yo desconocía para permitirme relacionarlos con otros que yo no podía sino conocer. Mucho tiempo después advertí que el primer mandamiento de su magistrado era convertir al interlocutor en la persona más importante del mundo. Bastaba que alguien lanzase al aire una palabra para que él, con fruición, la cazase al vuelo y la devolviera multiplicada con todos sus significados; para Rama, enseñar y aprender formaban parte de una misma ceremonia dialéctica, y jamás conocí a nadie que se internara con tanta pasión en las dos aguas a la vez.

Aunque tenía sólo nueve años más que yo, sabía tanto como si me 1levara noventa. Ya por entonces había fundado y dirigido la revista $\mathrm{Cli}$ namen, había editado Entregas de la Licorne, proyectaba el lanzamiento de la editorial Arca, dirigía la sección literaria de Marcha, dictaba clases en innumerables colegios y estaba completando la escritura de su segunda novela, Tierra sin mapa ${ }^{5}$. Después de la primera, iOh sombra puritana! (1951), y del consabido peregrinaje a París, había terminado un par de obras de teatro, Lucrecia (1957) y La inundación (1958). La tercera, Queridos amigos ${ }^{6}$, estaba casi lista.

Esos abusos de energía le brotaban también de la conversación, como una electricidad. Hacia las diez de la mañana de aquel primer día en Mon-

${ }^{5}$ Alvaro Barros-Lémez, que ha rescatado algunos de los trabajos de creación escritos por Rama en esa época, observa en su artículo «Angel Rama, narrador» (Hispamérica, año XIII, núm. 39, 1984, pp. 49-54) que ciertos temas claves -el enfrentamiento entre materia y espíritu, la soledad, la incomunicación y la incapacidad para romperlas, la mujer como centro de atracción-atención- enlazan a Tierra sin mapa con la primera novela de Rama y con los cuentos de Desde esta orilla, un libro cuya publicación anunciaba la editorial Alfa en 1961 y que «nunca llegó a ver la luz». Arturo Sergio Visca opinó sobre Tierra sin mapa en su Antología del cuento uruguayo contemporáneo (1962), publicada al año siguiente:

«... globalmente considerada, la novela nos parece falsa por su tema y sus personajes: aisladamente, el recuerdo rescata algunas escenas de limpia ejecución e intensa escritura.»

${ }^{6}$ La Comedia Nacional uruguaya estrenó Queridos amigos en 1961. En su artículo de Hispamérica, núm. 39, Barros-Lémez evoca la ácida crítica que Rodríguez Monegal consagró en Marcha a iOh sombra puritana!:

«Quizá por estar escrita en primera persona y ser tan personal pueda ser extravagante y aburrida... Como promesa de narrador - promesa a cumplirse, seguramente, a largo plazo- este libro tiene un fragmento en que se cuenta una salida bajo la lluvia que parece nacer de algo más verdadero que la comezón de estrenarse cuanto antes en la narrativa.»

El comentario fue publicado el 21 de marzo de 1952. Rama tenía veinticinco años. 
tevideo habíamos pasado ya revista (él lo hizo: yo tan sólo acotaba) a los últimos discos de Louis Armstrong, a las películas de Leopoldo Torre Nilsson, a los sorprendentes cuentos de un argentino ignoto que vivía en París como traductor de la Unesco y al tumulto de libros sobre el peronismo que inflamaba el ambiente intelectual argentino. En la casa de la calle Timbó, donde vivía por entonces, Rama desplazaba los encantos de su talento sin que nada pareciera fatigarlo: como si fuese a la vez un acróbata y un maratonista. Recuerdo el fugaz momento en que hojeó, al pasar, la Antología poética argentina de Borges, Bioy Casares y Silvina Ocampo, y se detuvo en algunos versos que se le desmoronaron sobre la lengua, enfermos de ceniza. Le oí preguntar entonces qué sobreviviría de toda esa hojarasca, sobre cuáles de aquellas líneas (salvadas ya del olvido entre otras miles) se posarían los ojos de cien años más tarde.

-Quién se la llevará por fin - repitió, callando la única palabra que hacía falta, "gloria», con la misma curiosidad metafísica que yo le descubriría casi veinte años después en Caracas y al cabo de otros cinco en su casa de Washington-. Quién, entre todos, se llevará la gloria.

Mucho de lo que escribió desde entonces fue para dar sosiego a esa pregunta. Como no tenía miedo a equivocarse (por lo contrario, entendía que sin error no hay grandeza: que los errores nos salvan), perfeccionó el olfato para descubrir antes que nadie a los creadores verdaderos, y a partir de esa gimnasia, para ver símbolos y tensiones inexploradas en obras que habían pasado ya por el filtro de todos los análisis.

Entre 1975 y 1979 acudí con frecuencia a su apartamento de Caracas, en las Colinas de Bello Monte, donde los malabarismos de su inteligencia se las arreglaban para no desoír a los amigos mientras escribía un par de brillantes ensayos al mes, concertaba las ediciones de la Biblioteca Ayacucho, salía y entraba de sus conferencias en Puerto Rico, preparaba las clases -inolvidables clases, me han dicho- para la Universidad Central de Venezuela, organizaba la revista Escritura y terminaba enzarzándose en polémicas feroces sobre la cultura venezolana. No pocas excomuniones le valieron esas polémicas, porque tampoco era fácil descubrir, bajo la caparazón de sus reproches, las señales de un amor intenso por el país que lo había cobijado en el exilio y que, a la postre, elegiría como su patria final.

Fue sólo entonces, en Caracas, cuando advertí que Rama no había renunciado a la creación literaria, sino que la expresaba de una manera heterodoxa, a través de sus formulaciones críticas. Observé que así como el autor de ficciones trabaja sobre el cuerpo de la realidad, Rama aplicaba sus sentimientos al cuerpo de los textos como si se tratara de criaturas vivas, de paisajes: entrando en ellos, comprometiendo a los textos con su 
pasión. No a la inversa: no eran los textos los que suscitaban en él determinadas miradas. Era su mirada, la de Rama, la que con frecuencia iluminaba los textos. Una obra examinada por él era como el cuadro central de una exposición maravillosamente montada y no el objeto perdido de un desordenado zoco.

¿De qué manera explicarlo? Quien con mayor lucidez parece haberlo advertido es Nelson Osorio en su artículo «Angel Rama y el estudio comprensivo de la literatura latinoamericana» ${ }^{7}$. Allí dice Osorio:

Para el modo como entendía Rama la crítica, la investigación no es una actividad independiente, sino que forma parte sustancial y constituye el basamento de su ejercicio; y la resolución ensayística no era sino la modalidad de discurso en que esta crítica organizaba los resultados de su investigación, para convertirse en transmisión más amplia y fertilizadora.

La crítica, por consiguiente, puede considerarse en su caso el ejercicio intelectual creador que funciona como eje de articulación de la tarea del investigador y del discurso del ensayista. La investigación es el único fundamento que puede dar objetividad y rigor científico al trabajo crítico; y el ensayo es una de las modalidades en que puede encauzarse el producto intelectual que de este ejercicio nace.

La caracterización se completa con una reflexión del propio Rama que aparece en el prólogo a La novela en América Latina. Panoramas 19201980:

Ocurre que si la crítica no constituye las obras, sí constituye la literatura, entendida como un corpus orgánico en que se expresa una cultura, una nación, el pueblo de un continente, pues la misma América Latina sigue siendo un proyecto intelectual vanguardista que espera su realización concreta ${ }^{8}$.

El párrafo -ya lo advierte Osorio- exhala un «aroma de herejía». Para los académicos de que hablaba Rubén Darío en su «Letanía de nuestro señor Don Quijote», las libertades de una crítica que se elige a sí misma como acto de creación suelen ser nefandas conspiraciones contra la seriedad científica.

7 Tomado de Prismal/Cabral, núms. 12-13, University of Maryland, pp. 103-114. El artículo es transcripción de la ponencia de Nelson Osorio durante las «Jornadas de Homenaje a Angel Rama», organizadas por el Departamento de Teoría Literaria, Universidad Central de Venezuela, en febrero de 1984.

${ }^{8}$ Edición citada, pp. 15-16. 
Rama se preocupó muy bien de neutralizar esos prejuicios antes de que le cayeran encima. Nunca empleó un término sin precisar sus alcances y definir sus significados. No sólo apuntaló cada observación general con análisis particulares concretos (como quedó dicho), sino que mantuvo al día su aguda percepción lingüística y se complació en recurrir a comparaciones internas y a simetrías con una soltura que pueden permitirse sólo los eruditos. Un ejemplo admirable es el análisis sobre «la arrolladora fuerza asociativa» de la lengua infantil en Los ríos profundos, de José María Arguedas, y sobre los enlaces entre conciencia subjetiva y realidad objetiva que se alcanzan en la misma novela a través de un juego de ritmos y melodías.

Estar en todo, penetrarlo todo, acabó por ser la otra huella digital de Rama. Jean Franco ha narrado que, cuando lo visitó en París, lo último que oyó fueron los fragores de su máquina de escribir, que competía con el tecleo incesante de una máquina contigua, la de Marta Traba. Una imagen idéntica brota de la carta póstuma que le mandó Augusto Roa Bastos desde Toulouse, cuya intimidad de lenguaje se resiste a toda glosa:

Hube de retroceder entonces a la memoria. Esos días, esos años, esas vidas. Fragmentos. Latidos. Delirios de la presunción. Como cuando venías, Angel, a Buenos Aires, y te alojabas en mi cuchitril de la calle Vera, en Almagro, y comenzabas a trabajar desde la madrugada en tu pequeña máquina de escribir puesta sobre las almohadas atrapando al vuelo esos pensamientos de la noche. Deseo insondable. Como si hubieras trabajado toda la vida en ese último minuto para recomenzar en el siguiente ${ }^{9}$.

A mí, en cambio, se me ha sembrado en la imaginación el recuerdo de una noche de invierno en su estudio del Cairo Building, cuando el Departamento de Inmigración estaba condenándolo a marcharse para siempre de Washington. En medio de los desasosiegos de la inminente mudanza, Rama llevaba en alto su inquebrantable humor, su curiosidad por el futuro, el hambre por todas las palabras y todos los sentimientos de este mundo. En alguna parte sonaba el concierto número 21 de Mozart. Yo, distraído, hojeaba los últimos libros de dos grandes narradores latinoamericanos. De pronto, Angel soltó una carcajada, recitó de memoria las: frases iniciales de ambas novelas, con los bigotes en ristre y los ojos alzados hacia un horizonte de manuscritos universitarios, y repitió la eterna, gozosa pregunta de la juventud:

— ¿Quién se la llevará: qué te parece?

\footnotetext{
9 Augusto Roa Bastos, «Les debía carta...», en Prismal/Cabral, núms. 12-13, University of Maryland, pp. 138-139.
} 
Todo examen de la literatura partía en Rama de lo que él mismo ca-racterizó como una "perspectiva culturalista e histórica» ${ }^{10}$. Esa lente de observación tiene cristales marxistas, por supuesto, pero el espectro solar que Rama estudió a través de ella guarda poca relación con el mecanismo. y el dogmatismo teórico que suele afectar a los maestros de tal corriente.

Ya en sus primeros textos puso en claro que la ideología impregna toda la actividad del hombre, aun en los procesos menos conscientes de la escritura, y que analizar una obra dejando de lado esa huella fundamental deforma sus intenciones y modifica su sentido último. Reformulando el' viejo postulado de Mme. de Staël, según el cual la literatura es, siempre, cabal expresión de la sociedad, Rama advirtió que los condicionamientos impuestos por la economía a los pueblos vencidos o marginales producían, obviamente, una literatura marcada por esa impronta. Era uno de sus méritos mayores: atreverse a expresar en voz alta, por primera vez, las ideas que flotaban en el aire desde hacía mucho tiempo. Así, escribe en «La modernización literaria latinoamericana»:

Si los latinoamericanos respondieron al mismo impulso que había movido a los europeos cuando la transformación capitalista industrial de sus sociedades, eran sin embargo sensiblemente diferentes las características de su integración a la economía mundial y por ende diferentes: las características de su producción artística.

Citando a Marx expresamente, Rama concibe la imaginación como fuerza transformadora y todo discurso estético como portador de ideología. De ahí también que la crítica -0 , desde su particular perspectiva, sobre todo la crítica - deba necesariamente usar el recurso de la imaginación: ser a la vez creadora y re-creadora. En cierto modo, Rama asignó a la crítica la difícil función (a la vez poética y sociológica) de revelar los cuerpos en su relación con la corriente que los arrastra: no sólo como afluentes que acrecientan y enriquecen esa corriente, sino también como

${ }^{10}$ Así lo declara explícitamente en el ensayo «La modernización literaria latinoamericana»:

«Asumimos, por lo tanto, una concepción culturalista e histórica, a la que subyace el reconocimiento de la pluralidad de áreas culturales del continente (aun dentro de un mismo país, como se ve en el Brasil) y la pluralidad de estratos socioculturales que en cualquiera de ellas puede encontrarse y originan diversas modulaciones de las mismas condiciones básicas del periodo.»

Más allá de la precisión taxativa, Rama aplicó la misma visión a otras épocas, como se advierte en Los gauchipoliticos rioplatenses y, sobre todo, en Los dictadores latinoamericanos. 
fuerzas de cambio que modifican su color y desvían su curso. Un objeto de constante investigación era para Rama el influjo de los comportamientos sociales sobre los comportamientos de la lengua, o la inevitable correspondencia que los enlazaba. Así, en su análisis de la sociedad «novohispana» que se forjó medio siglo después de la toma de Tenochtitlán, advierte la intensidad de esa relación dialéctica:

... la sociedad novohispana del siglo xvi no es una entidad homogénea, sino que comporta plurales estratos que se articulan velozmente, a los cuales atribuimos la capacidad de generar formas culturales específicas e igualmente estratificadas, aunque dentro de su pertenencia a un área común sobre la cual operan con distinta fuerza los grupos de una dinámica cultural que, desde una perspectiva contemporánea, podríamos equiparar a la lucha de clases. [Del mismo modo] debemos reconocer que dichos estratos tienen comportamientos lingüísticos diferenciales que incluso entran en pugna y dan motivo a represiones y revueltas, fuerzas encontradas que trabajan sobre la lengua $y$, en la medida en que ésta es, además, historia, se superponen a ella y la constituyen, sin que nunca sea fija y estable debido a la incesante producción ${ }^{11}$.

Reflexiones tan torrenciales no podían encasillarse dentro de una línea teórica cerrada. Para respirar a pleno pulmón, Rama necesita moverse con libertad: utilizar esta o aquella categoría del pensamiento, una definición semántica, una frase musical o un mito clásico cuando advertía la pertinencia del recurso, sin detenerse a considerar las ortodoxias de la moda.

De ahí que no sea fácil ir desgranando los rasgos centrales de su método crítico, pues tales rasgos iban transformándose de acuerdo con el texto y con su época, como un guante flexible. Su visión englobadora, totalizadora de la escritura dentro de un sistema de relaciones culturales que no deja de lado ningún interés del hombre -ni las ciencias o la política, ni menos aún la economía o los medios de comunicación-, permite definir a Rama como un humanista en el sentido que Juan Luis Vives y Erasmo conferían al término, y en el que admirablemente pudo expresar Shakespeare en Hamlet: un observador ávido de cada respiración del hombre ${ }^{12}$.

Asumir, como lo hizo Rama, una visión según la cual ninguna esfera del conocimiento se mueve aislada de las otras esferas planetarias, supone

${ }^{11}$ En «La señal de Jonás sobre el pueblo mexicano», originalmente publicado en 1a revista Escritura, Caracas, julio-diciembre 1980, pp. 193-194.

${ }^{12}$ El humanismo es, en sus formas extremas, una celebración antropocéntrica: una indagación de las claves del hombre. J. A. Cuddon sugiere que tal punto de vista está bien expresado por Hamlet, en Hamlet, II, escena 2. 
resignarse a ser un forzado de la erudición. Rama lo era, con esa voracidad y esa gimnasia que sólo se comprenden a la luz de su pasado periodístico, si bien el incesante ir y venir de datos y relaciones que caracterizaba sus artículos nunca es ocioso. Sólo al advertir con cuánta exactitud apelaba a Kurt Weil y a George Gershwin para desnudar el mundo polifónico de Arguedas, o cuán útiles son sus referencias al demonismo de Ingmar Bergman y a la transposición de las formas en las Meninas de Picasso para adentrarse en la génesis de La guerra del fin del mundo, tan sólo entonces, pues, queda claro que para Rama la erudición era una linterna de geólogo y no los reflectores de un escenario.

Un texto es, en su sistema de lectura, caja de resonancia de todos los sonidos del mundo: a través del texto es posible detectar el concierto de disciplinas tan dispares como la arquitectura y la gastronomía o el vínculo sutil de un estribillo vanguardista con culturas remotas y lenguas extinguidas. De una relación puede inferirse otra, y otra más, como los pañuelos que fluyen de la manga de un prestidigitador. La crítica, así, es un juego de nunca acabar: una exploración que desconoce la meta. Tal vez sólo admitiendo esa fascinación laberíntica puedan entenderse los infinitos repasos y correcciones que Rama desplegaba sobre sus artículos cada vez que debía publicarlos (también infinitamente), sin que tales operaciones cesaran ni aun cuando parecían asumir, en un libro, su forma definitiva. Hay por lo menos cuatro versiones de «El boom en perspectiva» (como ponencia para el Wilson Center, en Washington D. C.; como capítulo de un libro colectivo, Más allá del 'boom', editado por Marcha en México; como artículo en la revista Escritura, número 7, y como fragmento de su propio libro La novela latinoamericana), sin que pueda asegurarse que Rama considerase la última como definitiva.

Es que ni siquiera el escrupuloso análisis de una frase en todas las direcciones posibles lo dejaba satisfecho. Para que la crítica de un texto alcanzase su plenitud había que analizar ese texto a la luz de los fenómenos culturales de su tiempo, re-examinando las opiniones que había suscitado en el momento histórico que apareció, y pasándolo por el cedazo de todas las teorías posibles. Pero, ya se sabe, siempre habrá una nueva reflexión que obligará a reconsiderar el texto por enésima vez. Y así hasta el agotamiento.

Acaso esta imagen de Rama desfigure un tanto la del infatigable animador y polemista que también fue: oculte su desdén por la solemnidad y el espontáneo vuelo de sus pensamientos (tan semejante a la soltura de los grandes cantantes, que exhalan su música sin esfuerzo, como si tan sólo estuvieran respirando). Porque en la crítica encontraba una sensualidad (Barthes hablaría de «placer») que alcanzaba su mejor nivel en los 
combates cuerpo a cuerpo: cuando era preciso refutar una idea, contestar a un desafío.

Si se observan esas operaciones en detalle, algunos leitmotive saldrán de inmediato al encuentro de quienes leen. Porque en la obra de Rama, como en la de todo creador, hay constantes, obsesiones, estribillos que pasan de un texto a otro. Uno de los más notables es la refutación de las idées reçues, de esos lugares comunes consagrados como verdad por una larguísima tradición crítica. A la inversa de la mayoría de sus colegas, que parten de un cliché indiscutido y organizan sus reflexiones en torno a él, el rechazo del lugar común es en Rama la consecuencia lógica del hilo de pensamiento que van siguiendo sus artículos. Elegir una vía no convencional desemboca, por fuerza, en postulados que tampoco son convencionales. Por eso es frecuente que las refutaciones broten sólo al final de los textos, naturalmente.

Vale la pena enumerar con cierto detenimiento esas embestidas al lugar común, tanto por lo que hay en ellas de juego y alegría como por su fuerza estimulante. Rama endereza sus dardos contra dos zonas muy precisas de la convención académica: las «verdades» que nadie sabe dónde ni cuándo se originaron, cuyos redobles van repitiéndose de un crítico a otro, monótonamente; y las "verdades» lanzadas al viento por un autor en particular y admitidas desde siempre como canónicas.

$\mathrm{Al}$ segundo grupo corresponde su ya célebre polémica con Mario Vargas Llosa sobre la idea romántica de que un narrador no elige sus temas, sino que es elegido por ellos ${ }^{13}$. Una señal de que Rama jamás soltaba la presa es el regreso a ese mismo argumento, una década después, cuando derramó sobre La guerra del fin del mundo las más encendidas alabanzas de toda su carrera, aprovechando el lance para subrayar que, con esa novela, su antiguo contendiente no hacía más que darle la razón:

Una vez polemizamos Mario Vargas Llosa y yo a propósito del género novela. El estaba entonces imbuido del subjetivismo astuto de sus primeras creaciones, más atraído por la génesis oscura de las fuerzas desencadenantes (los dichosos fantasmas o demonios) que por los productos objetivos y sus efectos sobre el medio. Yo trataba de argumentar, recurriendo a las fuentes del género, acerca de que la novela ha sido

${ }^{13}$ Originalmente publicada en Marcha durante el curso de 1972 y suscitada por un libro de Vargas Llosa - Gabriel García Márquez: historia de un deicidio (Barcelona: Barral Editores, 1971)-, la polémica fue reproducida en media docena de periódicos y finalmente recogida en un volumen de 90 páginas por CorregidorMarcha ediciones, en Buenos Aires, diciembre de 1973, con el título García Márquez y la problemática de la novela. 
y es un arma. Pienso que con esta obra me ha dado la razón, pues ella está construida como un arma ${ }^{14}$.

Menos famosas son sus enfáticas refutaciones a Federico de Onís y a Pedro Henríquez Ureña, incluidas ambas en «La modernización literaria latinoamericana». A las variaciones sobre el concepto de «literatura pura» con que los dos caracterizan el período 1890-1920, Rama opone la tesis de que los escritores «fueron francamente políticos e ideólogos», sumidos no en la marea de esa "crisis universal de las letras y el espíritu» que marca el fin del siglo XIX (en opinión de Onís), sino en un proceso de vigorosa maduración que, por un lado, les permitió «integrarse a la cultura universal mediante sistemas expresivos comunes»y, por otro, los tornó «capaces de resguardar la cultura regional» ${ }^{15}$.

Pero es en su combate contra el primer grupo de idées reçues donde Rama se anota las victorias más memorables, tal vez porque allí los prejuicios eran más difíciles de desarraigar y su imaginación, por lo tanto, podía trabajar con mayor tenacidad. Si ya en Marcha se alzó, ocasionalmente, contra la certeza de que el modernismo había brotado ex nihilo, en sus prólogos de la última época sobre clásicos hispanoamericanos del siglo XIX, editados en España por el Círculo de Lectores, volvió una y otra vez sobre la idea, incluyendo nuevos argumentos:

... desde la perspectiva actual [el modernismo fue] una verdadera resurrección artística con recuperación de fuentes que se produjo conjuntamente con la acelerada modernización. El acierto de esta solución positiva no puede atribuirse solamente al talento de los escritores de ese período finisecular, sino también a la lenta consolidación que había producido la autonomía literaria del continente. Sin ella no hubiera habido diálogo, ni plataforma para diseñar una nueva estética, ni establecido sistemas de comunicación, ni un esbozo de nacionalidad con su particular régimen de asuntos, pensamientos, sabores, hábitos, complicidades. Más aún: la nueva estética — del modernismo- se propone la continentalización, por encima de las fronteras nacionales, respondiendo al universalismo de la hora. Tampoco lo hubiera podido encarar si ya no se hubiera alcanzado esa autonomía propuesta en 1822 por Bello ${ }^{16}$.

${ }^{14}$ De la introducción de A. R. a La guerra del fin del mundo (Barcelona: Círculo de Lectores, 1983), p. xv.

${ }^{15}$ Es también notable su réplica a la Historia personal del 'boom', de José Donoso, incluida en el ensayo «El boom en perspectiva».

${ }^{16}$ De «El manifiesto fundacional», prólogo al volumen Clásicos hispanoamericanos. Siglo XIX (Barcelona: Círculo de Lectores, 1983). 
Para no incurrir en una enumeración interminable, basta con describir unos pocos lugares comunes y anotar las herramientas de que se sirvió Rama para barrerlos de la topografía literaria: de eso:

- ¿La poesía es un género no ideológico y suprahistórico? Nada

... la poesía se nos aparece como un «aleph» donde se unifican, por equivalencias estructuraies más que contenidistas, los variados niveles de la realidad cultural y de los campos donde opera el psiquismo, presentándose así como una proposición integradora y reguladora de los discursos, colectivos o individuales, en que acostumbramos repartir la praxis ${ }^{17}$.

Y en el contexto de la afirmación asoma una batería impresionante de referencias bibliográficas, que arrancan de la Vita nuova de Dante y van hasta los artículos de Robert Weimann sobre el estructuralismo francés y la historia literaria.

- ¿La poesía gauchesca es una germinación directa de la poesía de los payadores? No:

La generación de 1872 (que debemos designar en ambas márgenes del Plata como la generación racionalista) cumple una estricta operación literaria, al margen de los niveles artísticos a veces paupérrimos por obra de un equipo de escritores (a veces versificadores, simplemente) ajenos a los pretendidos orígenes de la gauchesca; que la remonta a los cantos espontáneos en torno a los fogones o a la figura legendaria de los payadores ${ }^{18}$.

- ¿Y no está por ventura teñido de cierto elitismo el prejuicio que identifica el magma original de la sociedad mexicana con los criollos hijos de conquistadores, quien «en el último tercio del siglo XVI transformaron en literatura su resentimiento y frustración, enarbolando su hidalguía y las hazañas de padres o abuelos»? Sí, la idea no está exenta de un «dejo aristocratizante», pues

... ni eran todos los criollos (minuciosamente contados por Dorantes de Carranza, no llegaban a mil personas) ni compartían los intereses de importantes sectores de la población. Al contrario: es justamente en sus escritos donde se ofrece, con reprobación y alarma manifiesta, el inicial

\footnotetext{
${ }^{17}$ «Indagación de la ideología en la poesía (Los dípticos seriados de Versos sencillos)», en Revista Iberoamericana, XLVI, julio-diciembre 1980, p. 355.

${ }^{18}$ Los gauchipoliticos rioplatenses (Buenos Aires: Centro Editor de América Latina, 1982), p. 106.
} 
retrato de ese pueblo mexicano que estaba surgiendo desordenadamente en los intersticios, frecuentemente ilegales, de una sociedad que se disciplinaba, estratificaba e institucionalizaba, bajo la construcción de la monarquía absoluta, para contribuir ancilarmente al proyecto capitalista en curso entonces en Europa ${ }^{19}$.

- ¿Por qué aceptar sin un análisis a fondo la idea de que el boom narrativo de los años sesenta brotó en el desierto, sin relación alguna con la novela que lo precedió, como si de pronto se abriese un abismo entre las lenguas y las estructuras del relato, un antes y un ahora fáciles de discernir? No. Para Rama, en el tejido de la cultura no hay cortes transversales ni árboles de generación espontánea, y son sin duda más los puntos de contacto entre García Márquez o Cortázar con sus precursores que las líneas de separación. A lo sumo, la distinción más clara es cuantitativa: existe un público más vasto que antes, más interesado en leer «hacia adentro», y un mercado editorial más abierto a la producción interna.

Otra obsesión constante en la obra de Rama es la percepción de matices, el brumoso crepúsctilo que marca el tránsito de una ideología a otra, el mezclado estuario de una corriente que declina con un mar que surge.

Un buen ejemplo es la ponencia que presentó al Coloquio sobre la nueva narrativa latinoamericana, organizado por él mismo a fines de 1979 en el Wilison Center de Washington D. C. Allí sistematizó por primera vez la intrincada geografía de un fenómeno literario que distaba entonces (y dista todavía) de haberse agotado, y sobre el que no cesan de brotar líneas interpretativas diversas y aun opuestas. Desgranando un aluvión de informaciones que estaban al alcance de cualquiera, pero que sólo él sabía procesar, Rama describió las nuances entre las editoriales «culturales», oficiales, pequeñas empresas privadas y multinacionales del libro que habían prosperado y fracasado en los años del boom, subrayando admirablemente la lenta sustitución de los títulos extranjeros en los catálogos por otros de autores nacionales y latinoamericanos. Fue un fenómeno que consagró -advertía Rama- a editoriales como Fabril, Sudamericana, Losada, Fondo de Cultura, Seix Barral y Joaquín Mortiz, pero que también las empujó en algunos casos a la extinción y a la ruina.

Rama intuyó la importancia de ese texto y lo pulió cada vez que decidía re-publicarlo, como ya se ha dicho. A comienzos de 1980 lo editó como separata de la revista Escritura y distribuyó las copias a estudiantes universitarios, periodistas culturales y narradores de todo el continente, con un entusiasmo que solía reservar sólo para las obras ajenas. Tenía

19 «La señal de Jonás sobre el pueblo mexicano», cfr. Escritura, número citado, p. 179. 
razón. Allí se desplazan de un párrafo a otro todos los recursos de su libertad y las disciplinas de su erudición. En algunas de las mejores páginas del ensayo matiza una vez más a los autores del boom según se hayan o no afanado en elaborar un discurso crítico. En otras, baraja las estadísticas de las casas editoriales (una fuente que los académicos suelen menospreciar) para describir el acceso de la literatura latinoamericana a circuitos intocados de lectores, así como las curiosas mareas que infunden éxito a un libro determinado sólo porque otro libro del mismo autor lo arrastró. $\mathrm{El}$ efecto de las estadísticas aplicadas a la producción literaria es notable: atreviéndose a usarlas con desenfado, Rama consigue revelar, de una sola vez, el estallido de la profesionalización del escritor, la brusca conversión de las editoriales, el extraño desvío del interés de los lectores más hacia el narrador superstar (como lo llamaría Jean Franco en ese mismo Coloquio) que hacia la propia obra.

Es verdad que ninguno de tales recursos es nuevo para Rama. La búsqueda de matices lo había llevado a señalar, en sus estudios sobre el romanticismo, que los modelos utópicos iniciales se diluyen cuando quienes los propusieron, desde la oposición, ascienden al poder. Y las estadísticas le habían servido para describir el estímulo de la demanda popular sobre los creadores al estudiar los cuarenta y ocho mil ejemplares de Martín Fierro que se publicaron entre 1872 y 1878 :

Nunca se había visto nada semejante en América Latina: ese público que con tanto tesón buscaron los románticos argentinos sin encontrarlo, debiendo conformarse con el cautivo que les ofrecían los periódicos o revistas, irrumpe repentinamente con la desconcertante comprobación de que procede de esas comunidades rurales y suburbanas donde nadie pensaba encontrar un lector o un auditor. Incluso el número de ejemplares vendidos da escasa idea del número de lectores (la costumbre que se instaura de leer el Martín Fierro en público para los analfabetos) y los muchos más que lo aprenden de memoria hasta hacer de él, en sustitución de las remanencias folklóricas, una suerte de colección de máximas en verso que se pueden utilizar en los más variados momentos de la vida cotidiana ${ }^{20}$.

Pero si esos recursos se desplegaron con mayor amplitud en el estudio sobre el boom, es porque allí, precisamente, se le ofreció a Rama la ocasión de abarcar en su plenitud uno de los grandes procesos contemporá-

${ }^{20}$ Si bien la cita, tomada de «El manifiesto fundacional», data de 1983, la reflexión sobre las cifras de venta de Martín Fierro aparece ya en su artículo "Literatura y sociedad» (1976), y antes todavía, en la ponencia presentada al XV Congreso Iberoamericano de Literatura, Lima, 1971. 
neos y de servir como guía o punto de referencia para la que bautizaría él como «generación de los novísimos» ${ }^{21}$. Los grandes procesos, las líneas maestras de la creación: tal era el campo que prefería y no el estudio entomológico de un texto o de un autor aislados de su contexto de producción. Aun en los prólogos a La guerra del fin del mundo y Crónica de una muerte anunciada, que datan de la última y fértil época en que se asoció al Círculo de Lectores, o en los más tempranos libros que consagró a dos venezolanos arquetípicos, Salvador Garmendia y la narrativa informativa ${ }^{22}$ y El universo simbólico de José Antonio Ramos Sucre ${ }^{23}$, Rama encontró la manera de desentrañar, a través de una obra particular, la atmósfera intelectual y las obsesiones de la época entera. Así, el ensayo sobre Ramos Sucre aclara de una vez la elisión quirúrgica de los pronombres relativos: el famoso «que» estigmatizado por Rafael María Baralt, así como «cual», «cuyo», «cuantos» y su completa familia de femeninos y plurales. También se sirve de la obra de Ramos Sucre para emprender uno de los más formidables análisis del poema en prosa modernista, para estudiar las transposiciones del cuento hacia este otro género, y viceversa, y para observar las mareas simbolistas, parnasianas y hasta wagnerianas que confluyeron en una Caracas hipnotizada por el absolutismo de Juan Vicente Gómez ${ }^{24}$.

${ }^{21}$ En el prólogo a Novísimos narradores hispanoamericanos en marcha, 19641980 (titulado «Los contestatarios del poder») (México: Marcha editores, 1981), pp. 9-11.

${ }^{22}$ Caracas: Ediciones de la Universidad Central de Venezuela, 1975.

${ }^{23}$ Cumaná, Venezuela: Ediciones de la Universidad de Oriente, 1978. Este libro ganó el premio de Ensayo en la II Bienal José Antonio Ramos Sucre, organizada por esa Universidad.

${ }^{24}$ Los numerosos artículos y libros que Rama consagró al modernismo incluyen excelentes estudios de fenómenos particulares. Así, en «La dialéctica de la modernidad en José Martí», publicado en Estudios martianos (Memoria del Seminario José Martí, 1971) (San Juan: Editorial Universitaria, Universidad de Puerto Rico, 1974), pp. 129-197, traza un notable retrato de Martí como intérprete de su colectividad social:

«... para Martí no podía disociarse la creación intelectual o artística de las restantes formas de la vida cultural, se tratara de política, de sociología, de moral, aunque no intuyó la energía y el centralismo del factor económico, situando en cambio el punto de apoyo de la totalidad en la órbita de la filosofía de la historia. Por cualquiera de los rumbos del conocimiento él llegaba a leer el mismo relato, descubriendo estricta correspondencia entre disciplinas que hasta ese momento habían estado, en América Latina, compartimentadas» (p. 136).

Más vertientes aún asoman en su libro Rubén Dario y el modernismo (Caracas: Ediciones de la Biblioteca, Universidad Central de Venezuela, 1970), en el cual estu- 
Aun en los tiempos de máximo apogeo - $-y$ de la moda: excluyente, casi dogmática - de la lectura semiótica y estructuralista, Rama insistió, con desafiante heterodoxia, en examinar las condiciones materiales de producción de toda obra y los factores de recepción, enfatizando la importancia del lector como árbitro (Instanz en el lenguaje de Hans Robert Jauss) de «una nueva historia de la literatura». Yendo cada vez más lejos en esa búsqueda, terminó por descubrir un enorme claro: una encrucijada del bosque -o del desierto- donde se perdían todas las huellas. Ese inexplorado continente era Brasil. Al internarse, advirtió Rama que muchos de los troncos nacidos en Latinoamérica estaban floreciendo en Río, São Paulo, Porto Alegre y el sertón, o viceversa, con lo cual permitió que una cultura artificialmente divorciada comenzase a integrarse. Diez volúmenes entre los primeros cien de la Biblioteca Ayacucho atestiguan la pasión de Rama por un encuentro al que no habían prestado atención los críticos de uno y otro lado, con las excepciones de Haroldo de Campos, Antonio Cándido y Emir Rodríguez Monegal, quien a finales de los años sesenta abrió las páginas de su revista Mundo nuevo a las narraciones de Guimarães Rosa y Clarice Lispector.

Una vez más, a diferencia de sus congéneres, Rama no se dejaba deslumbrar por los fenómenos aislados, sino que se mantenía a la busca de las sutiles vías de enlace, de los inadvertidos vientos unificadores. ¿Cómo entender, si no, su obstinación para que en los volúmenes colectivos de la Biblioteca Ayacucho -Poesía de la independencia, Pensamiento políitico de la emancipación, Pensamiento de la ilustración, Pensamiento positivista latinoamericano - la cultura brasileña tuviese la presencia que se le concedía en los tratados de intercambio panamericanos, pero se le negaba en los textos y cátedras universitarios? Otro tanto sucedió con Puerto Rico, donde Rama enseñó entre 1970 y 1972, y cuyas singulares características de nación que no es Estado suscitaron en él reflexiones tan lúcidas (y osadas: sobre todo para quien estaba pidiendo la residencia en los Estados Unidos) como las de su prólogo a La independencia de Puerto Rico: razón y lucha, el combativo ensayo de Rubén Berríos Martínez ${ }^{25}$.

La pasión por averiguar quién, al fin de cuentas, «se la llevaría» (¿la eternidad, la fama, la memoria de los pueblos?), quién prevalecerá ma-

dia muy a fondo el conocimiento de su mercado que los poetas modernistas adquirieron a través del periodismo, dignificando, de paso, un género nuevo.

Rama volvió sobre el tema en «La canción del oro de la clase emergente», incluido en el libro póstumo Las máscaras democráticas del modernismo (Montevideo: Ediciones de la Fundación Angel Rama, 1985).

${ }^{25}$ Editado en San Juan por P. I. P. en 1983. El prólogo de Rama se titula «Solidaridad con Puerto Rico». 
ñana entre las gentes, engendró en Rama tan infatigable sed por estar en. todo, por no perderse nada, por adelantarse a los dictámenes de su tiempo, que allí, en esas señales de vitalidad y fortaleza es donde paradójicamente asoman las mayores debilidades de su obra.

Casi no se detuvo a corregir lo que escribía, exaltado por la facilidad con que sus reflexiones llegaban siempre al blanco, sin advertir que en esa carrera voraz el lenguaje tropezaba con demasiados adverbios de modo, que no terminaba de abrirse paso en la red de oraciones subordinadas, que perdía - por el desaliño- parte de su enorme fuerza persuasiva.

Es verdad que al final vivió tiempos de apremio. Con cierto fácil psicologismo podría inferirse que los by-pass injertados en su corazón en 1978 le advirtieron que la muerte está siempre a la vuelta de la esquina y que sólo afanándose, prodigándose, podría tal vez conjurarla. Pero eso no fue lo que lo echó a correr. Hay que buscar el detonante en el rechazo a su solicitud de residencia en los Estados Unidos, donde confiaba en poner término a sus trajines de nómada. Fue en ese punto cuando Rama no quiso darse ya la menor tregua. Se sumió en la escritura como quien acata una fatalidad, un vicio. En tales tensiones extremas del temperamento le brotaron algunas de sus reflexiones más brillantes y de sus prosas más abigarradas.

Aspiró de un envión toda la libertad que andaba suelta y la desplegó alegremente en las últimas ponencias y artículos de su vida. Contra todos. los prejuicios de la tradición crítica, se atrevió a formular advertencias. y predicciones sin la menor cautela:

No son necesarios los dones de Casandra para anunciar que [ $L a$ guerra del fin del mundo] tendrá millones de lectores y que en la renovada apuesta a cien años vista se la mencionará como una de las novelas claves de esta segunda mitad del siglo xx que vio la triunfal expansión del género en el continente ${ }^{26}$.

Hizo, por fin, lo que siempre había querido: jugó como un niño genial en un gabinete de química concertando las teorías de Roman Jakobson con las de Wolfgang Iser, imaginando los descalabros que Roberto de las Carreras — «heraldo del amor libre»- pudo haber desatado a comienzos de siglo en «la toldería de Montevideo», exaltando olímpicamente a novísimos narradores que se le apagaban entre los dedos e ignorando sin remordimiento a otros que brillaban en la lengua de todo el mundo,

${ }^{26}$ De la introducción a La guerra del fin del mundo, ed. cit., p. Irr. 
no por mera soberbia de la inteligencia, sino para no traicionar aquello en lo que creía.

Alguna vez, en su apartamento de Caracas, la conversación derivó hacia los estragos que la fatalidad rilkeana de la muerte propia había causado entre los literatos latinoamericanos, tan fascinados siempre por las efusiones románticas. Recuerdo con nitidez aquella tarde, atormentada por el canto de las cigarras. Desde algún cuarto de la casa fluía, otra vez, la música de Mozart. El aire se movía con pereza. Tuve la impresión de que Rama, sentado en un sillón blanco, a la sombra de cuadros que contaban novelas - Botero, Cuevas, Jacobo Borges-, había recalado al fin en su hogar último, en el único verdadero: la desembocadura en la que confluían los hijos, las ternuras y los libros.

-No me quedará otro remedio que morir en un aula, enseñando -dijo, como de paso.

Fue lo que sucedió, exactamente, el 27 de noviembre de 1983, cuando los aquelarres de un avión que cayó en las afueras de Madrid lo apagaron para siempre. Iban a bordo Marta Traba, Jorge Ibargüengoitia, Manuel Scorza. Rama, no hay por qué dudarlo, estaría descubriendo ante sus alucinados oyentes algún olvidado delirio modernista, el fulgor de una novela sin publicar, la inadvertida ironía de una tragedia neoclásica. No podía imaginar que su aula estaba allí y que ésa era su lección final: que el fogonazo del avión apagaría las fugaces palabras de aquella mañana, pero encendería todas las otras palabras de su vida. 